\title{
GAYFEROS: DE CABALLERO A DEMONIO (O DEL ROMANCE AL CONJURO DE LOS AÑOS 1570)
}

Hace algún tiempo, al investigar sobre documentos inquisitoriales del Tribunal de Córdoba que corresponden al siglo xvi, tuve ocasión de leer unas relaciones de causas que se refieren a las famosas hechiceras de Montilla, entre quienes figuraba Leonor Rodríguez, la célebre Camacha ${ }^{1}$. Esas hechiceras fueron condenadas por el Santo Oficio a salir al auto de fe que se celebró en la ciudad andaluza el día 8 de diciembre de 1572 y sufrieron diversas penas ${ }^{2}$. La actuación que se les atribuyó y la pública lectura de la sentencia, así como el público castigo que se les infligió, contribuyeron a darles una sospechosa notoriedad por toda Andalucía.

Cervantes, que estuvo en Montilla en 1591 y 1592, se enteró de lo ocurrido y trasladó al Coloquio de los perros el personaje de la Camacha.

Sabido es que, en la novela cervantina, la Cañizares, una hechicera seguidora de esa bruja, le cuenta al perro Berganza que la madre de éste, llamada la Montiela, era discípula de la misma maestra y llegó a superarla. Por ello, cuando la Montiela, preñada, estuvo en el trance del parto, la Camacha le sirvió de comadrona y se vengó de ella, mostrándole que había parido dos

${ }^{1}$ Estas relaciones pueden verse ahora en el volumen de documentos del Tribunal inquisitorial de Córdoba, recopilados por Rafael García BoIX, Autos de fe y causas de la Inquisición de Córdoba, Diputación Provincial, Córdoba, 1983, pp. 91-100. Remitiré a estas relaciones impresas bajo la forma: Causas de Córdoba.

${ }^{2} \mathrm{He}$ aquí por ejemplo la pena que se aplicó a la Camacha: "Que salga al Auto en forma de penitente, con coroza en la cabeza, con insignias de hechicera y abjure de levi y le den cien azotes en Córdoba y ciento en Montilla, de donde sea desterrada por diez años, con cinco leguas a la redonda y sirva los dos primeros años de los diez en un hospital de Córdoba, cual se le señalare y pague ciento cincuenta ducados al Receptor"' (Causas de Córdoba, p. 96). 
perritos ${ }^{3}$. Éstos sólo podrían recobrar el ser auténtico cuando se cumpliera la profecía enunciada por la sospechosa partera:
Volverán en su forma verdadera cuando vieren con presta diligencia derribar los soberbios levantados, y alzar a los humildes abatidos con poderosa mano para hacello ${ }^{4}$.

Tengo que confesar que lo que me llevó a examinar las relaciones de causas de las hechiceras de Montilla (a las cuales había aludido ya Agustín González de Amezúa en su edición de El casamiento engañoso y El coloquio de los perros ${ }^{5}$ ) fue precisamente el recuerdo del texto cervantino. Pero lo que primero me llamó la atención fue que la Camacha, al hacer sus conjuros, invocaba a los demonios de la manera siguiente: "Lucifer y Satanás, Belcebú, Barrabás y Gayferos, aposentador mayor de los infiernos... 6 .

Si los cuatro primeros diablos figuran a menudo en los conjuros que ha reunido y publicado Sebastián Cirac Estopañán ${ }^{7}$ o en los que también yo he juntado, sacados asimismo de los Archivos de la Inquisición, la invocación al último, al cual recurría igualmente Isabel Martín, compañera de la Camacha ${ }^{8}$, no deja de plantear un problema. En efecto, hasta ahora no parece que se haya encontrado mención de ningún demonio que llevara ese nom-

${ }^{3}$ Utilizo la ed. crítica con introd. y notas de Agustín González de Amezúa, El casamiento engañoso y El coloquio de los perros, Bailly-Baillière, Madrid, 1912, véanse pp. 334 ss.

${ }^{4}$ Ibid, p. 337. La profecía cervantina de la Camacha tiene su origen en la Eneida de Virgilio (vv. 851-853). Ya la había utilizado San Agustín en La ciudad de Dios (lib. V, cap. XII). También aparece, por ejemplo, en el episodio del villano del Danubio elaborado por fray Antonio de Guevara e incluido en su Marco Aurelio de 1528 y en su Relox de Príncipes de 1529; sobre el particular, cf. Augustin Redondo, Antonio de Guevara (1480?'-1545) et l'Espagne de son temps. De la carrière officielle aux oeuvres politico-morales, Droz, Genève, 1976, p. 667. En el Quijote, Cervantes ha de :jugar con varios elementos de esta profecía; véase, por ejemplo, I, 46.

${ }^{5}$ Véase la introducción de A. GonZÁLEz de AMEzúa a El casamiento engañoso y El coloquio de los perros, pp. 171 ss. Cf. asimismo Álvvaro HuERGa, "El proceso inquisitorial contra la Camacha", CICer, pp. 453-469.

${ }^{6}$ Causas de Córdoba, p. 94.

7 Sebastián Cirac Estopañán, Los procesos de hechicerías en la Inquisición de Castilla la Nueva (Tribunales de Toledo y Cuenca), C.S.I.C., Madrid, 1942; véanse, por ejemplo, pp. 123-124.

${ }^{8}$ Causas de Córdoba, pp. 98, 139, 150, etcétera. 
bre. Claro está que no se puede dejar de pensar en Gayferos, aquel famoso héroe del romance tan difundido en siglo Xvi que empieza: "Estávase la condesa,/ en su estrado asentada..." 9 .

El tema del romance (o mejor dicho de los romances, ya que el relato se halla separado en dos partes vinculadas entre sí y publicadas juntas en los pliegos sueltos y en los cancioneros) era muy conocido. Recuérdese que Gayferos, de corta edad, queda huérfano de padre porque el conde don Galván lo ha matado, a traición, para casarse con su mujer. Pero la condesa incita al hijo a vengar la muerte del padre, cuando sea mayor. Oído esto por don Galván, manda a sus escuderos que se lleven a Gayferos y lo maten. Sin embargo, los servidores se apiadan del niño y, gracias a un subterfugio, lo dejan con vida. No obstante, el jovenzuelo tiene que huir de tierra en tierra hasta llegar al lugar donde está su tío don Roldán. Éste lo cría y cuando Gayferos puede ya llevar armas, ambos van a vengarse del conde traidor, disfrazados de romeros. El mozo degüella al padrastro, alcanzando de tal modo la apetecida venganza. Triunfa de la adversa fortuna y recobra su posición social al ser reconocido por su madre cuando le dice su nombre y le presenta la mano mutilada ${ }^{10}$.

Pero, ¿qué tendrá que ver este romance con el conjuro? ¿Cómo habrá podido tranformarse Gayferos en demonio?

Es preciso volver a examinar el romance. Para ello, utilizaré la versión más corriente en el siglo xvi, la que figura en el Cancionero de romances, impreso en Amberes, sin año, aunque data aproximadamente de $1550^{11}$. forma:

Don Galván ordena a los escuderos que maten al niño de esta

${ }^{9}$ Acerca de dicha difusión, véanse Antonio Rodríguez Moñino, Diccionario bibliográfico de pliegos sueltos poéticos, Castalia, Madrid, 1970, núms. 506, 706, 1061, 1062 y 1064.

${ }^{10}$ Puede verse el texto del romance - de los dos romances en realidad-, por ejemplo en Romancero, ed. Michelle Debax, Alhambra, Madrid, 1982, pp. 235-241.

${ }^{11}$ Cancionero de romances, impreso en Amberes, sin año; ed. facs. con una introd. de R. Menéndez Pidal, C.S.I.C., Madrid, 1945, f. $103 \mathrm{v}^{\circ}-107 \mathrm{r}^{\circ}$. El trozo citado está en el f. $104 \mathrm{r}^{\circ}$. 
corten le el pie del estribo,

la mano del gavilán, saquen le ambos los ojos por más seguro andar, y el dedo y el coraçón traed me lo por señal (vv. 41-46).

Como los servidores ven acercarse a la perrita de la condesa, se apoderan del animal, lo matan, le sacan el corazón y se lo llevan al conde con el dedo que le cortan a Gayferos.

El héroe expulsado del hogar, cuando niño, por el padrastro (o la madrastra), quien ha mandado que le corten el dedo o la mano, le saquen los ojos y le arranquen el corazón; la sustitución de estos órganos por los de un animal; la fuga del héroe; el encuentro en otro reino con un maestro iniciador que cuida de él y le proporciona un saber o un objeto mágico gracias al cual podrá eliminar el daño sufrido; la vuelta del héroe de incógnito; el reconocimiento gracias a la marca o al estigma recibido; el castigo del malvado y el triunfo del héroe, son otros tantos motivos folklóricos. Han sido recogidos en parte por Stith Thompson ${ }^{12}$ y analizados sistemáticamente por Vladimir Propp quien, apoyándose en el estudio de los cuentos maravillosos rusos, los ha enlazado con el simbolismo de la iniciación cuyo origen se remontaría, al parecer, al chamanismo de las épocas prehistóricas ${ }^{13}$. Esos

12 Véase Stith Thompson, Motif-Index on folk literature, $2^{\mathrm{a}}$ ed., Indiana University Press, Bloomington-London, 1966, motivo K. 512.2 ("cambio de corazones por compasión del que ha de cometer el crimen") y motivo H. 57.2 ("dedo cortado como señal de la muerte del héroe" e "identificación gracias al dedo mandado"). Véase también AntTI Aarne y STITH ThOMPSON, The types of the folktale, $2^{\text {a }}$ ed., Academia Scientiarum Fennica, Helsinki, 1973, F.F.C. núm. 184, tipos 671 y 709 ("cambio de corazones").

${ }^{13}$ Véase Vladimir PROPP, Las raices históricas del cuento, trad. José Martín Arancibia, Fundamentos, Madrid, 1974, pp. 114 ss. ("héroe expulsado del hogar"); pp. 116 ss. ("el niño conducido al bosque", es decir a la "muerte iniciática"); pp. 118 ss. ("el padrastro o la madrastra es el que rechaza al niño"); pp. 127 ss. ("las pruebas iniciáticas"); pp. 127-128 ("el dedo meñique cortado"); p. 129 ("la mano cortada"); p. 129 ("la ceguera del héroe"); p. 136 ("el cambio de corazones"); p. 146 ("el maestro que cuida al muchacho está en otro reino"), etc. Cf. también VLADIMIR PROPP, Morfología del cuento, $2^{\mathrm{a}}$ ed., trad. Lourdes Ortiz, Fundamentos, Madrid, 1974, pp. $42-48$ ("la madrastra ordena a su servidor que estrangule a su hijastro durante un paseo"; " "el agresor exige en general que le lleven el hígado y el corazón del muerto"; "el héroe condenado a muerte es liberado secretamente porque el servi- 
motivos, efectivamente, aparecen en varios cuentos populares españoles $^{14}$.

Pero lo que nos interesa todavía más es el valor simbólico que cobran los diferentes elementos del episodio si se relacionan con ritos sociales y mágicos de exclusión, que utilizan el mismo sistema de referencias míticas.

Cortarle al niño el pie del estribo y la mano del gavilán -o sea la mano derecha, la que empuña la espada - es impedir que Gayferos pueda montar a caballo y tomar la espada, lo que imposibilita toda forma de venganza posterior. Sobre todo, estas mutilaciones infamantes excluyen al héroe del grupo social al cual pertenece, el de los caballeros ${ }^{15}$; es, pues, quitarle la herencia que hubiera debido recibir.

Sacarle los ojos es, al cegarlo para siempre, apartarlo de su núcleo social, transformarlo en marginado errabundo. Es hacer imposible la venganza y además impedir, después del asesinato

dor mata en su lugar a un animal para llevar su corazón y su hígado como prueba de la muerte"); pp. 49 ss. ("el donante encontrado por el héroe, en el camino, el bosque, etc., le da un medio, generalmente mágico, que ha de permitirle solucionar el daño sufrido"); p. 68 ("el héroe llega de incógnito a su casa"); p. 70 ("el héroe es reconocido gracias a la marca que lleva"); p. 71 ("el agresor queda desenmascarado"), etcétera.

14 Véanse por ejemplo los cuentos siguientes: el de Blancanieves, muy conocido, en que el mayordomo, en vez de matar a la joven como se lo ha ordenado la madrastra, le deja con vida y sustituye la lengua y asadura por las de un corderito (cf. Aurelio M. Espinosa, Cuentos populares de Castilla y León, t. 1, C.S.I.C., Madrid, 1987, núm. 52); el de la mala madrastra (es en realidad una versión del precedente, en que la lengua y los ojos de la muchacha se hallan sustituidos por los de un perrito, ibid, núm. 53); el de la madrastra envidio$s a$ (otra versión del de Blancanieves, en que la lengua de la joven se ha reemplazado por la de una perrita, cf. AURELIo del Llano Roza DE AMPUDia, Cuentos asturianos recogidos de la tradición oral, Ed. de la Nueva España, Oviedo, 1975, núm. 29); el del suegro malvado (en que el rey manda matar al niño que, según la voz, sería su yerno, pero los dos hombres encargados de matarle se apiadan de él y llevan al soberano el corazón y los ojos de un perrito, véase LuIs CorTÉs, Cuentos populares salmantinos, Librería Cervantes, Salamanca, 1979, t. 1, núm. 71), etc. Como puede notarse, todos estos cuentos no son más que versiones o derivaciones del de Blancanieves.

${ }^{15}$ En el derecho romano, se aplicaba la pena de cortar la mano al parricida; las leyes españolas del siglo Xvi preveían tal pena infamante para el alevoso y la de cortar el pie para los hurtos importantes. Acerca de todo esto véase Augustin REDONDO, "Mutilations et marques corporelles d'infamie dans la Castille du Xvie siècle", en Actas del Coloquio Internacional sobre "Le corps dans la société espagnole des xvie et xuiì siècles", Paris, 1988, en prensa en las Publications de la Sorbonne. 
complementario del niño, que pueda seguir representando una posibilidad de venganza simbólica pues, según diversas creencias, los muertos que se entierran con los ojos abiertos miran y vigilan a los vivos ${ }^{16}$.

Por último, apoderarse del corazón del difunto es ser dueño de la fuerza vital del individuo y hacer que el espíritu del muerto no pueda manifestarse. De ahí la importancia que cobra el dedo de la mano cortada que se le ha de entregar a don Galván. Ese dedo será el del corazón (recuérdese que en el romance las dos palabras van juntas: "y el dedo y el corazón traedme", lo que en alguna versión será: "y el dedo del corazón traedme"). Se trata, pues, del dedo anular. He aquí, en efecto, lo que el doctor Juan Fragoso escribe en su Cirugía universal de 1581:

El más notable y aventajado de todos los dedos es el anular [...] por vezindad y consentimiento que tiene con el coraçón ${ }^{17}$.

A principios del siglo XviI, Sebastián de Covarrubias añade en el artículo anillo de su Tesoro:

Y particularmente se traýan los anillos en el dedo cercano al meñique, en la mano izquierda [ . . ] porque en la sectión del cuerpo humano hallaron los anatomistas un nervento delicado, que va desde aquel dedo al coracón y por él comunica, assí el oro como la piedra su virtud, con que le conforta ${ }^{18}$.

Cortar el dedo es pues impedir toda comunicación con el corazón, es oponerse a la circulación de la fuerza vital o sea del espíritu.

De tal modo, nos encontramos frente a ritos de exclusión de carácter social y mágico a un tiempo, que corresponden a tres niveles de separación: exclusión social, exclusión física, exclusión espiritual. Rechazar socialmente a Gayferos es despojarlo de su ser verdadero, transformarlo en un excluido, condenarlo a errar por un espacio "salvaje" fuera del espacio "social y cultural" del

${ }^{16}$ Véase Mircea Eliade, Histoire des croyances et des idées religieuses, Payot, Paris, 1983, t. 2, p. 118.

${ }^{17}$ Cito por CÉSAR E. DüBleR, La materia médica de "Diocórides". Glosario médico castellano del siglo xvi, Barcelona, 1954, p. 907.

${ }_{18}$ Tesoro de la lengua castellana, ed. Martín de Riquer, Horta, Barcelona, 1943 , p. $121 \mathrm{~b}$. 
grupo $^{19}$; excluirlo físicamente es quitarle la vida; excluirlo espiritualmente es lanzarlo definitivamente al mundo infernal. De ahí que estos ritos se verifiquen fuera del espacio social, ya que este último es, al contrario, el de la integración, o, empleando los términos de Lévi-Strauss, el que corresponde al paso de la "natura" a la "cultura" 20.

Por otra parte, la aparición de la perrita participa del mismo sistema. En efecto, no hay que olvidar la primera función mítica del perro: la de guiar a las ánimas, en la noche de la muerte, hacia el Más Allá. Por ello el Cancerbero guardaba el umbral del Otro Mundo, y en la mitología griega, Hécate, la divinidad de las tinieblas y la gran hechicera, podía cobrar la forma de un perro y se encontraba en las encrucijadas, rodeada de una jauría de canes infernales. De la misma manera, el Jinete Negro -o sea el Diablo - que capitaneaba la espantosa estantigua salida del infierno, iba acompañado de una jauría endemoniada ${ }^{21}$. Y en los conjuros de las hechiceras, los tres galgos corredores aparecen con frecuencia al lado de los diablos ${ }^{22}$. No es pues de extrañar que fue en el Coloquio de los perros, la diabólica Camacha pueda mostrarle a Cañizares que ha parido dos cachorros. Pero, para volver a nuestro romance, la perrita aparece como el doble de Gayferos el excluido, y la sustitución pone de relieve los vínculos que existen entre el héroe y el universo del Más Allá. Por ello tal vez, en las dos versiones del romance recogidas en época contemporánea (en 1915 y 1916) en Tetuán, y cuyo conocimiento debo a la amistad de Diego Catalán, el padre de Gayferos entra en una cueva de la cual sólo sale su caballo ${ }^{23}$, lo que hace pensar que el caso

${ }^{19}$ Me sirvo, claro está, de los conceptos muy conocidos utilizados por Claude LÉVI-STRAUSS, quien maneja la oposición "natura".-"cultura" (véase su libro Les structures élémentaires de la parenté, $2^{\mathrm{a}}$ ed., Maison des Sciences de l'Homme-Mouton, Paris-La Haye, 1973).

${ }^{20} I d$.

21 Véase Augustin Redondo, "La “Mesnie Hellequin» et la Estantigua: les traditions hispaniques de la "Chasse sauvage" et leur résurgence dans le Don Quichotte', Traditions populaires et diffusion de la culture en Espagne (xvil-xviie siècles), Presses Universitaires, Bordeaux, 1983, pp. 1-27.

${ }^{22}$ Véanse S. Cirac Estopañán, op. cit., pp. 119, 128, 143, etc., y Causas de Córdoba, p. 98. En la causa seguida en 1616 contra la Gerónima, hospitalera de Tordelaguna, invocadora de diablos, un testigo declaró haber visto bajar en su casa, por la escalera del portal, "un gran perraço negro que nunca le había visto" (cfi la introd. de A. GonzÁlez de AMEZÚA, op. cit., p. 169, nota 26).

${ }^{23}$ Por carta del 20 de febrero de 1987, Diego Catalán me ha comunicado 
de don Alonso de Aguilar, vástago de la familia de los marqueses de Priego, transformado en caballo por la Camacha, según lo referido por el libro de los Casos notables de la ciudad de Córdoba, escrito hacia $1618^{24}$. Sabido es que la cueva es el lugar privilegiado de contacto con el Más Allá ${ }^{25}$ y asimismo, el caballo es otro animal asociado a la muerte y al viaje iniciático; a él le corresponde guiar las ánimas de los difuntos hacia el Otro Mundo. Hécate podría tomar no sólo la forma de un perro sino también la de una yegua; además, en la Edad Media europea, las ánimas de los finados eran representadas con alguna frecuencia por caballos y el infernal Jinete de la endiablada hueste antigua montaba un caballo negro 26 .

La sustitución por la perra impide que Gayferos sea víctima de dos de las tres exclusiones que le amenazaban: las relacionadas con la muerte física y con el Otro Mundo. No obstante, no desaparece la exclusión social o sea la muerte social. El héroe viene a ser un desterrado y tiene que salir de los límites del condado ("vos ýos de aquesta tierra,/ y en ella no parezcáys más": vv. 71-72) y se transforma en un ser errante ("yr vos eys de tierra en tierra'": v. 75; "Gayferos desconsolado/ por esse mundo se va": vv. 77-78).

En la realidad de la Edad Media y el Renacimiento, esos ritos de exclusión social, con ruptura de los vínculos que unían la persona a la comunidad, y muerte simbólica, se verificaban con relación a los leprosos, los cuales se hallaban obligados a errar -y luego a estar recluidos - en un espacio "salvaje" apartado del espacio social de la comunidad ${ }^{27}$. No es casual que el nombre de

generosamente los dos textos de la tradición sefardí recogidos en Tetuán en 1915 y 1916. En la versión de 1915, dice el conde acerca del padre de Gayferos: "Yo le vi entrar a una cueva mas no le vide asomarse/vi salir a su caballo y él no le vide asomare". La versión de 1916 indica: "Yo le vi entrar a una cueva y no le vide asomarse/vi salir a su caballo y él no se asomare".

${ }^{24}$ Véase lo apuntado sobre el particular por A. GonzÁLEZ DE AMEZÚa y A. Huerga en los trabajos citados supra nota 5. El libro de los Casos notables de la ciudad de Córdoba lo publicó Ángel González Palencia en Madrid, en 1949 (Sociedad de Bibliófilos Españoles, $2^{a}$ época, t. 24).

${ }^{25}$ Véanse por ejemplo los trabajos de Mircea Eliade, Traité d'histoire des religions, Payot, Paris, 1968, pp. 214 ss.; e Initiations, rites, sociétés secrètes, Gallimard, Paris, 1976.

${ }^{26}$ Véase Jean-Paul Clébert, Bestiaire fabuleux, Albin Michel, Paris, 1971, pp. 100 ss.

${ }^{27}$ Sobre el particular, véanse los trabajos de Françoise BéRIAC: su tesis 
nuestro héroe (Gayferos) evoque el de los gafos, palabra que ha servido para designar a los leprosos y seguía empleándose todavía en el siglo xvi. Covarrubias recoge el vocablo y le dedica un largo artículo en que pone de relieve la exclusión de la que venimos hablando; se refiere también a la creencia muy difundida según la cual la lepra iba unida a una gran culpa y correspondía a la expiación de un horrendo pecado. El leproso era pues la representación del mal cristiano y aparecía como un ser más o menos diabólico ${ }^{28}$. Verdad es que su propio nombre es particularmente evocador ya que está directamente relacionado con la gafa o sea con el gancho, por la forma encorvada que da a los dedos del leproso la contracción de sus nervios ${ }^{29}$. También recuerda la garfa o sea la garra de las aves de presa ${ }^{30}$. Es lo que Covarrubias indica a las claras:

El gafo es un enfermo de cierto género de lepra muy malo, el qual ultra de la pudrición y corrupción que causa en el cuerpo royendo el cuero y las carnes, encoge los nervios de manos y pies, y particularmente los llaman gafos a los tales enfermos por encorvarseles los dedos de las manos como a las aves de rapiña ${ }^{31}$.

doctoral Lèpre et société en Aquitaine (xiii -xvie siècles) presentada en la Sorbona en 1983 (un ejemplar en la Biblioteca de la Sorbona), pp. 180 ss., 293 ss., y su libro Histoire des lépreux au Moyen Age. Une société d'exclus, Imago, Paris, 1988, pp. 129 ss. Todavía no deja de tener algún interés la obra de FRANCISQUE MICHEL, Histoire des races maudites de la France et de l'Espagne, Paris, 1847. En España, faltan trabajos de conjunto acerca de los leprosos. No obstante, cf. el libro de J. Tolivar Faes, Hospitales de leprosos en Asturias durante las edades media y moderna, Instituto de Estudios Asturianos, Oviedo, 1966; en las pp. 303306 se hace referencia a la reclusión conventual de los leprosos. Sobre el grupo de los agotes, que se encontraban en la diócesis de Jaca, al NO de Aragón y en la alta Navarra y vivieron completamente apartados del resto de la sociedad hasta finales del siglo XVI porque se les consideraba como leprosos, véanse Florencio IdOATe, Documentos sobre agotes y grupos afines en Navarra, Institución Príncipe de Viana, Pamplona, 1973, y María del Carmen Aguirre DeLlauX, Los agotes, Diputación Foral de Navarra-Institución Príncipe de Viana-C.S.I.C., Pamplona, 1977.

${ }^{28}$ Véase Tesoro de la lengua castellana de Covarrubias (pp. 619a-619b, s.v. gafo). Sobre la lepra relacionada con el pecado y el leproso como símbolo del pecador, cf. también F. BÉRIAC, Histoire des lépreux. . , pp. 87 ss., 115 ss., etcétera.

${ }^{29}$ Véase F. BÉRIAC, Lèpre et société. . ., pp. 121-131; Histoire des lépreux. . , pp. 28-29. Cf. además DCECH, s.v. gafo.

${ }^{30}$ Cf. $D C E C H$, s.v. garra.

${ }^{31}$ Cf. Covarnubias, Tesoro..., s.v. gafo, p. 618a. 
La presencia de esas garras tan demoniacas no podía sino acentuar, en las mentalidades populares, los vínculos establecidos entre los leprosos y el mundo diabólico: el gafo venía a ser, en cierto modo, una encarnación del diablo.

Además, hay que notar que la lepra nerviosa se caracteriza también por mutilaciones diversas que afectan principalmente a los dedos de las manos, dejando las extremidades de los miembros reducidas a muñones. ¿No es esta imagen de Gayferos la que se impone cuando en el romance se habla de la amputación de la mano, y más adelante cuando el héroe se queda sin el dedo? Por último, esa mano que don Galván manda que le corten a Gayferos (o sea la mano derecha, la que agarra la empuñadura de la espada) aparece bajo la forma de "mano del gavilán". En el contexto que se va evocando, el empleo de tal expresión no podía sino hacer pensar en el ave de cetrería y en sus terribles garras (recuérdese que el gavilán era también el garfio de hierro que se usaba para aferrar las embarcaciones).

Ahora ya podemos estudiar el conjuro de la Camacha y de su compañera Isabel Martín. Pero antes quisiera indicar que Gayferos el excluido, el gafo, no puede volver al espacio social del cual se le ha apartado sino valiéndose de un hábito de romero (o sea negando aparentemente su propio ser). Y sólo puede recuperar su ser auténtico e integrarse en el grupo social que le corresponde - anulando la canina trasmutación- cuando ha vengado la muerte del padre y restablecido la legitimidad del linaje, tan importante en el siglo xvI. Es decir que, según la cervantina predicción de la Camacha, ha vuelto a su forma verdadera cuando los "soberbios levantados" han sido derribados y alzados los "humildes abatidos",

Por lo que hace al conjuro de la Camacha, he aquí lo que se encuentra en la relación de causa que le corresponde (algo parecido hay en la de Isabel Rodríguez):

Confesó que deprendió de una hechicera, que en sus dedos del corazón de ambas manos vio por sus ojos tener uñas de águila, la oración de "Lucifer y Satanás y Belcebú y Barrabás y Gayferos, el aposentador mayor de los infiernos", diciendo lo que quieren que hagan los diablos, teniendo trece velas y habas y garbanzos; y que en tres miércoles, entre las once y las doce, había de salir sola, un pie calzado y otro descalzo, e ir a tres iglesias que tuviesen sacramento y echar una 
blanca o un chanflón de limosna en el cementerio de cada una; y que si a la ida no topase con un hombre, a la venida le toparía y le preguntase: "¿quién sois?" y le respondería: "Gayferos soy", y le había de decir: "dadme el alma" y ella le respondiese: "no, sino un miembro del dedo del corazón de la mano derecha", y se lo había de dar firmado de su nombre con la sangre del dicho dedo, y hecho esto, quedaba el diablo teniendo parte con ella; y que en señal que era del diablo aquel miembro, nacería entre la uña y la carne, una uña de águila ${ }^{32}$.

Mi intención no es hablar del sistema simbólico del conjuro, elaborado a partir de una mitología folklórica que ha dado lugar a varios estudios ${ }^{33}$, sino ver de qué manera el nuevo diablo, Gayferos, se ha incorporado a este sistema.

El conjuro implica una invocación previa, una llamada a la entidad conjurada que ha de apoyarse en un auténtico pacto. $\mathrm{Pa}$ ra recibir el poder necesario de la entidad convocada por la hechicera, ésta ha de someterse a un verdadero intercambio de tipo social, según el esquema del don y del contra-don descrito por Marcel Mauss ${ }^{34}$. Es decir que la hechicera tiene que dar algo (una blanca, un chanflón o, simbólicamente, un dedo) para que la entidad conjurada - aquí el diablo- responda a la llamada. Pero el conjuro aparece como un acto global en el que, en un primer tiempo, ha de verificarse una identificación completa y provisional entre la hechicera y el demonio para que las características y el poder de éste se le comuniquen a aquélla. De ahí que el cuerpo de la conjuradora sea a un tiempo agente y soporte de tal proceso y que la forma más completa de esta unión absoluta sea la cópula ("tener parte con él [= el diablo]", dice la relación citada).

${ }^{32}$ Causas de Córdoba, p. 95.

33 Véanse en particular los siguientes estudios: Carlo GinzBURG, Les batailles nocturnes: sorcellerie et rituels agraires en Frioul, xvi ${ }^{e}$-xviie siècles, trad. Giordana Charuty, Verdier, Lagrasse, 1980; "Présomptions sur le sabbat", $A E S C$, 39 (1984), 341-354; MircEa EliAde, "Quelques observations sur la sorcellerie européenne", cap. 2 de Occultisme, sorcellerie et modes culturelles, trad. Jean Malaquais, Gallimard, Paris, 1978; Julio Caro Baroja, Vidas mágicas e inquisición, Taurus, Madrid, 1967; FRANÇOIS DELPECH, "Système érotique et mythologie folklorique dans les conjuros amatorios (xvie-xviie siècles)", en A. Redondo (ed.), Amours légitimes-amours illégitimes en Espagne (xvie-xviie siècles), Pubis. de la Sorbonne, Paris, 1985, pp. 213-229.

${ }^{34}$ Véase Marcel Mauss, Sociologie et anthropologie, P.U.F., Paris, 1968, pp. 145 ss.: "Essai sur le don". Cf. también "Esquisse d'une théorie générale de la magie", pp. 3 ss. 
Además, este traslado de características va a provocar un vaivén, una transmisión invertida de particularidades: por ello la Camacha ha de entregarle a Gayferos "un dedo del corazón de la mano derecha" (recuérdese lo que se ha dicho acerca del héroe del romance), o sea el dedo que permite comunicar con el centro vital y sanguíneo de la relación especular que la hechicera mantiene con el demonio. De ahí que el pacto vaya firmado con sangre e implique la mención del nombre de la conjuradora, señal de la entrega total del ser de ésta al diablo ${ }^{35}$. Y como marca de posesión diabólica, la uña de águila, la garra (la que está vinculada con el gafo, según se ha visto) ha de nacerle a la hechicera entre la uña y la carne del dedo del corazón entregado de manera simbólica al demonio Gayferos.

Por otra parte, a la entidad a la cual se conjura se la insta a que vaya a un lugar sagrado y "salvaje" porque el conjuro corresponde a una transgresión de las normas del grupo social. Este lugar es muchas veces la Huerta de Moisén, el monte Sinaí, etc. ${ }^{36}$. Por su parte, Isabel Martín, la compañera de la Camacha, le pide a Marta la Mala que acuda "a la huerta de Gayferos"'37, recuerdo de ese espacio "salvaje" en el que, en el romance, se verificaban los ritos de exclusión de carácter social y mágico, a los cuales se ha hecho referencia ya.

El proceso evolutivo que se acaba de evocar sólo ha sido posible gracias a la gran difusión oral del romance de Gayferos y sólo se ha podido desarrollar en el marco de esta oralidad, ya que la Camacha era totalmente analfabeta ${ }^{38}$.

La transformación del personaje estudiado no se comprende

${ }^{35}$ No hay que perder de vista que, en la tradición judeo-cristiana, el nombre posee cierta cualidad mística y definitoria de la persona que lo lleva. Es lo que subraya FRAY LUIS de LEÓN en los Nombres de Cristo, cuando escribe: "El nombre es como imagen de la cosa de quien se dice, o la misma cosa disfrazada en otra manera", Obras completas, ed. Félix García, BAC, 1959, p. 398. Lo mismo dice el refrán apuntado por Gonzalo Correas: "el nonbre sigue al onbre", Vocabulario de refranes y frases proverbiales, ed. Louis Combet, Institut d'Études Ibériques et Ibéro-Américaines, Bordeaux, 1967, p. 90b.

${ }^{36}$ Véase S. Cirac Estopañán, op. cit., pp. 108, 110, 114, etcétera.

${ }^{37}$ Causas de Córdoba, p. 99.

38 Véase el documento del 3 de enero de 1573 citado por A. González DE AMEzúa (op. cit., p. 172), en que aparece que la Camacha no sabía firmar su nombre. 
sino tomando en cuenta las etimologías populares y el sistema fónico que relacionan el nombre del caballero, Gaxferos, con gafo (leproso) y gafa o garfa (garra), a pesar de que las verdaderas etimologías sean muy diferentes ${ }^{39}$. El encadenamiento evocado es el que permite pasar del universo aristocrático al de los leprosos, luego al de las aves de rapiña y por fin al del infierno. El sonido inicial, común en todos los casos, ha sido la razón de la permanencia de un motivo fundamental, el de la garra, el cual conduce a una duplicación: la uña de águila por un lado, el dedo encorvado por otro. Éste, bajo la forma del dedo cordial, remite al corazón y a la sangre. Así, todos los elementos en torno a los cuales gira el pacto diabólico implicado por el conjuro de la hechicera se relacionan dentro del mismo sistema mágico. No hay en esta ocasión ninguna ruptura entre la coherencia estructural específica de los dos tipos de "literatura oral": el romance de Gayferos y el conjuro de Gayferos.

Es posible, además, que la tradición rítmica y lírica del romance haya favorecido la transmutación puesta de relieve, ya que también existía (y existe) una tradición lírica e inspirada del conjuro, que integra asimismo elementos rítmicos que no se pueden percibir a través de la transcripción prosódica de la relación de causa.

Augustin Redondo

Université de la Sorbonne Nouvelle, Paris 